FITRAH Jurnal Kajian Ilmu-ilmu Keislaman

Vol.03 No. 1 Juni 2017

e-ISSN : 2460-2345, p-ISSN: 2442-6997

Web: jurnal.iain-padangsidimpuan.ac.id/index.php/F

\title{
NILAI-NILAI PENDIDIKAN ISLAM DALAM KISAH NABI NUH AS
}

SUFRIN EFENDI LUBIS

Dosen Fakultas Tarbiyah dan Ilmu Keguruan IAIN Padangsidimpuan

Email: sufrin.efendi@gmail.com

\begin{abstract}
The story of Prophet Nuh in the al Quran contains a lot of education values. Although this story has long been happened, but they are still relevant to be studied by educators, because the contents serve the values tobbe an example especially for dakwah and education. In the history of dakwah of the Prophet, we got valuable values for the future of dakwah and education, so that is any heavy obstacles come, it does not make us retreat and lazy, but steady and confidence. As for the education values found from dakwah the Prophet are: 1 . The value of aqidah, teaching us to believe in Allah, 2. The Moral values, by inviteing us to full of softness and patient, 3. The worship value, inviting for doing amar ma'ruf and nahi munkar, and educating children well.
\end{abstract}

Keywords: Value, Education, Story of Prophet Nuh

\section{Abstrak}

Kisah Nabi Nuh dalam al Qur'an memuat banyak nilai pendidikan. Meskipun cerita ini sudah lama terjadi, namun masih tetap relevan untuk dipelajari oleh pendidik, karena kandungannya memuat nilai yang patut dicontoh terutama untuk dakwah dan pendidikan. Pada sejarah dakwah Nabi Nuh, kita mendapat nilai berharga untuk masa depan dakwah dan pendidikan. Sehingga, apabila kita menemukan tantangan dalam jalan dakwah dan kendala yang menghadang, tidak membuat kita mundur dan malas, namun tetap tegar dan penuh keyakinan. Sedangkan untuk nilai pendidikan yang ditemukan dari dakwah Nabi Nuh, antara lain; 1. Nilai akidah, misalnya mengajak untuk percaya penuh kepada Allah, 2. Nilai moral, misalnya mengajak dengan penuh kelembutan dan kesabaran, 3. Nilai ibadah, misalnya menegakkan amar ma'ruf nahi mungkar, dan mendidik anak dengan baik.

Kata Kunci: nilai, pendidikan, cerita nabi Nuh.

\section{PENDAHULUAN}

Agama Islam yang dibawa oleh Nabi Muhammad Saw., merupakan agama yang bersifat syumul (sempurna), memiliki pengertian bahwa Islam mengandung 
FITR AH Jurnal Kajian Ilmu-ilmu Keislaman

Vol. 03 No. 1 Juli 2017

ajaran yang sangat komprehenshif; mencakup seluruh aspek kehidupan manusia, baik aspek pendidikan, sejarah, hukum, ekeonomi dan lain sebagainya.

Ajaran Islam yang komprehensif tersebut tertuang di dalam Al Quran sebagai kalam Ilahi, yang diwahyukan kepada Nabi Muhammad Saw., sebagai pembawa risalah untuk mengajarkannya kepada umat manusia, dan sekaligus sebagai pedoman hidup (way of life), sehingga manusia itu mendapatkan keselamatan di dunia dan di akhirat.

Untuk itu, manusia sangat perlu untuk menggali dan memahami kandungan dan pesan yang tersutar serta tersirat dari ayat-ayat al Quran dengan yang bersumber dari Allah Swt., yang bila diperlajari akan membantu manusia untuk menerapkan nilai-nilai yang dapat dijadikan pedoman dalam menyelesaikan berbagai problematikan kehidupan.

Di antara ayat-ayat Al Quran yang sangat perlu untuk dikaji adalah yang berbica tentang sejarah, kisah dan kejadian-kajadian di masa lampau. Bahkan kita suci Al Quran banyak memuat tentang sejarah. Hal ini mengisaratkan kepada kita betapa pentingnya mempelajari sejarah, memahami dan mengambil pelajaran-pelajaran penting dari sejarah serta menjadikannya sebagai bekal untuk menyelami kehidupan di masa mendatang agar mendapat kesuksesan dan kebahagiaan.

Berangkat dari poin itu, penulis tertarik untuk mengulas serta meneliti tentang “Nilai-Nilai Pendidikan Islam Dalam Kisah Nabi Nuh AS."

\section{PEMBAHASAN}

\section{Nilai-nilai Pendidikan Islam}

\section{a. Pengertian Nilai}

Segala ciptaan Allah Swt., yang ada di dunia ini memiliki nilai. Nilai merupakan sesuatu yang bersifat abstrak dan menjadi barometer terhadap sesuatu benda. Dengan adanya nilai seseorang dapat menyimpulkan bahwa sesuatu yang baik maupun sesuatu yang buruk, juga dengan nilai ini sesuatu dapat dibedakan dengan yang lainnya. Noor Syam ${ }^{1}$ mengatakan bahwa nilai adalah suatu penetapan atau suatu kualitas obyek yang menyangkut suatu jenis apresiasi atau minat. Sehingga nilai merupakan suatu otoritas ukuran dari subyek yang menilai.

1 Abd. Aziz, Filsafat Pendidikan Islam; Sebuah Gagasan Membangun Pendidikan Islam, (Yogyakarta: TERAS, 2009), hlm. 120 
Sedangkan menurut Muhaimin dan Abdul Mujib mengatakan bahwa, Nilai itu praktis dan efektif dalam jiwa dan tindakan manusia dan melembaga secara objektif di dalam masyarakat. ${ }^{2}$

Ungkapan yang menarik dari Webster bahwa nilai itu adalah "A value, says is a principle, standart quality regarde as worthwhile or desirable", yakni nilai adalah prinsip, standart, atau kualitas yang dipandang bermanfaat atau sangat diperlukan. Nilai adalah suatu keyakinan atau kepercayaan yang menjadi dasar bagi seseorang atau sekelompok orang untuk memilih tindakannya, atau menilai suatu yang bermakna atau tidak bermakna bagi kehidupannya. ${ }^{3}$

Dari pengertian nilai menurut beberapa para ahli di atas dapat disimpulkan bahwa nilai merupakan keyakinan dari seseorang untuk menjadikannya sebagai dasar dalam bertindak dan untuk menentukan apakah tindakan tersebut benar atau salah.

\section{b. Pengertian Pendidikan Islam}

Membenahi Ahklak merupakan misi utama diutusnya Rasulullah SAW. Oleh karena itu dalam Pendidikan Islam selalu berorientasi dalam pembentukan ahklak serta karakter positif peserta didik. Hal ini seperti yang jelaskan Nabi Muhammad Saw., bahwa misi kenabian tidak lepas dari upaya untuk meluruskan budi pekerjti menuju akhlak mulia. Nabi Muhammad Saw., bersada:

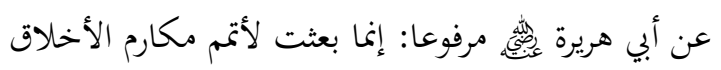

Bertolak dari hadits di atas Muhammad Naquib al-Attas mengatakan bahwa: "Pendidikan Islam merupakan upaya maksimal dari pihak pendidik terhadap peserta didik supaya mengenal hakikat Sang Pencipta serta mengenal kekuasanNya dengan penuh kesadaran. (H.R. Malim, Ahmad, Buhkari)

Secara etimologi istilah pendidikan memiliki tiga sumber kata dasar, yaitu kata tarbiyah, ta'lim dan ta'did. Namun menurut apabila mengaca pada misi akhir dari pendidikan kata yang paling tepat dan sesuai adalah kata tarbiyah, juga kata inilah yang paling banyak digunakan oleh orang arab. Sedangkan kata tarbiyah berakar dari tiga kata yang berbeda meskipun

2 Muhaimin dan Abdul Mujib, Pemikiran Pendidikan Islam, (Bandung: Trigenda Karya, 1993) hlm. 110

${ }^{3}$ Muhaimin, Pendidikan Islam: Mengurangi Benang Kusut Dunia Pendidikan, (Jakarta: PT Raja Grafindo Persada, 2006), hlm. 148 
FITR AH Jurnal Kajian Ilmu-ilmu Keislaman

Vol. 03 No. 1 Juli 2017

memiliki kesamaan pada tujuan. Pertama, dari kata, raba-yarbu yang bararti bertambah dan tumbuh. Kedua, dari kata, rabiya-yarba yang berarti tumbuh dan berkembang. Ketiga, dari kata, rabba-yarubbu yang berarti memperbaiki. Hal ini sesuai dengan yang disebutkan oleh An-Nahlawy. ${ }^{4}$

Sedangkan menurut terminologi Pendidikan Islam adalah segala upaya atau proses Pendidikan yang dilakukan untuk membimbing tingkah laku manusia, baik individu, maupun sosial untuk mengarahkan potensi, baik potensi dasar (fitrah), maupun ajar yang sesuai dengan fitrahnya melalui proses intelektual dan spiritual berlandaskan nilai Islam untuk mencapai kebahagian hidup di dunia dan akhirat. ${ }^{5}$

Senada dengan keterangan di atas, Arifin menyebutkan bahwa pandidikan Islam itu adalah "usaha orang dewasa muslim yang bertaqwa, secara sadar mengarahkan dan membimbing pertumbuhan serta perkembangan fitrah (kemampuan dasar) anak didik melalui ajaran Islam kearah titik maksimal pertumbuhan dan perkembangannya." 6

Sedangakan Menurut Mustafa al-Ghulayaini: "Pendidikan Islam adalah menanamkan ahklak yang mulia didalam jiwa anak pada masa pertumbuhannya dan menyiraminya dengan air pentunjuk dan nasehat, sehingga ahklak itu menjadi salah satu kemampuan(meresap dalam) jiwanya kemudian buahnya berwujud keutamaan, kebaikan, dan cinta bekerja untuk kemanfaatan tanah air". ${ }^{7}$

Menurut Syekh Muhammad Naquib al-Attas: "Pendidikan Islam adalah usaha yang dilakukan pendidik terhadap anak didik untuk pengenalan dan pengakuan tempat-tempat yang benar dari segala sesuatu didalam tatanan penciptaan sehingga membimbing ke arah pengenalan dan pengakuan akan tempat Tuhan yang tepat didalam tatanan wujud dan kepribadian".

Dari berbagai pendapat tentang pengertian pendidikan Islam di atas, penulis dapat menyimpulkan bahwa pendidikan Islam adalah rangkain upaya maksimal dari pihak pendidik untuk memberi pengarahan dan

${ }^{4}$ Lihat Abdurrahman An-Nahlawi, Usulu al-Tarbiyah al-Islamiyah wa Asaalibuha Fii al-Bait wa al-Madrasah wa al-Mujtama', (Dimasyq: Dar al-Fikr, 1979), Cet. Ke-1, hal. 4.

${ }^{5}$ Moh. Hailami \& Syamsul kurniawan, Studi Ilmu Pendidikan Islam, (Jogjakarta: Ar-Ruzz Media, 2012), hlm. 33

${ }^{6}$ M. Arifin, Ilmu Pendidikan Islam: Suatu Tinjauan Teoritis dan Praktis Berdasarkan Pendekatan Interdisipliner, (Jakata: bumi Aksara, 2000) hal.32.

${ }^{7}$ Hamdani Ihsan dan A. Fuad Ihsan, Filsafat Pendidikan Islam, (Bandung: CV. Pustaka Setia, 1998), hlm. 15 
bimbingan terhadap berbagai potensi yang dimiliki anak didik sehingga mencapai titik maksimal dalam pertumbuhan dan perkembangannya dengan berdasarkan ajaran Islam.

c. Ayat-ayat yang mengisahkan Dakwah Nabi Nuh AS

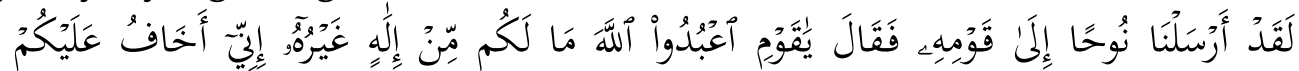

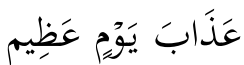

Artinya: Sesungguhnya Kami telah mengutus Nuh kepada kaumnya lalu ia berkata: "Wahai kaumku sembahlah Allah, sekali-kali tak ada Tuhan bagimu selain-Nya." Sesungguhnya (kalau kamu tidak menyembah Allah), aku takut kamu akan ditimpa azab hari yang besar (kiamat). (Q.S. al-A'raf: 59)

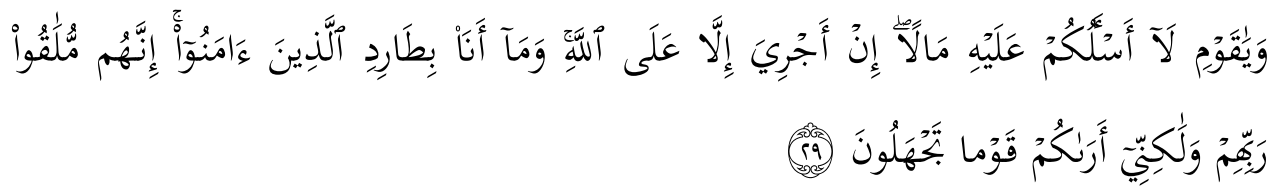

Artinya: dan (dia berkata): "Hai kaumku, aku tiada meminta harta benda kepada kamu (sebagai upah) bagi seruanku. Upahku hanyalah dari Allah dan aku sekali-kali tidak akan mengusir orang-orang yang telah beriman. Sesungguhnya mereka akan bertemu dengan Tuhannya, akan tetapi aku memandangmu suatu kaum yang tidak mengetahui". (Q.S. Hud: 29)

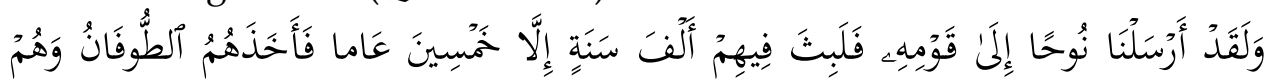

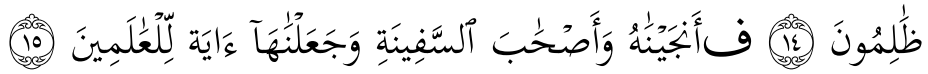

Artinya: dan Sesungguhnya Kami telah mengutus Nuh kepada kaumnya, Maka ia tinggal di antara mereka seribu tahun kurang lima puluh tahun. Maka mereka ditimpa banjir besar, dan mereka adalah orang-orang yang zalim. Maka Kami selamatkan Nuh dan penumpang-penumpang bahtera itu dan Kami jadikan Peristiwa itu pelajaran bagi semua umat manusia. (Q.S. alAnkabut: 14-15)

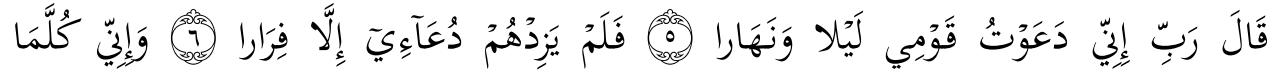

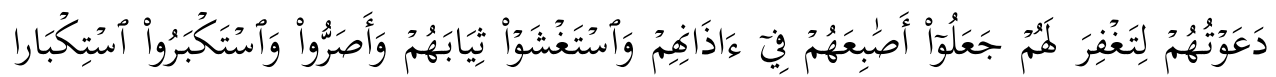

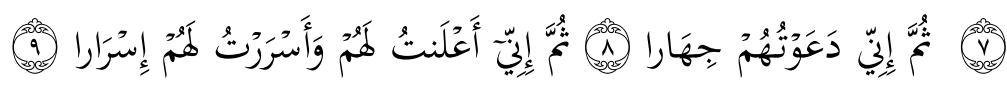

Artinya: Nuh berkata: "Ya Tuhanku Sesungguhnya aku telah menyeru kaumku malam dan siang. Maka seruanku itu hanyalah menambah mereka lari (dari kebenaran). dan Sesungguhnya 
FITR AH Jurnal Kajian Ilmu-ilmu Keislaman

Vol. 03 No. 1 Juli 2017

Setiap kali aku menyeru mereka (kepada iman) agar Engkau mengampuni mereka, mereka memasukkan anak jari mereka ke dalam telinganya dan menutupkan bajunya (kemukanya) dan mereka tetap (mengingkari) dan menyombongkan diri dengan sangat. kemudian Sesungguhnya aku telah menyeru mereka (kepada iman) dengan cara terang-terangan. kemudian Sesungguhnya aku (menyeru) mereka (lagi) dengan terangterangan dan dengan diam-diam. (Q.S. Nuh: 5-9)

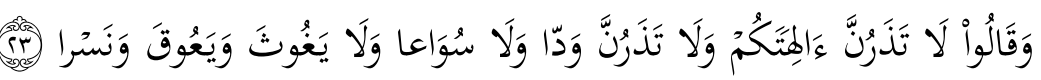

Artinya: dan mereka berkata: "Jangan sekali-kali kamu meninggalkan (penyembahan) tuhan-tuhan kamu dan jangan pula sekali-kali kamu meninggalkan (penyembahan) wadd, dan jangan pula suwwa', yaghuts, ya'uq dan nasr. (Q.S. Nuh: 23)

\section{Nilai-nilai Pendidikan dalam Dakwah Nabi Nuh}

\section{a. Nilai-nilai Pendidikan Akidah}

\section{1) Menanamkan Nilai Akidah}

Tauhid adalah merupakan misi utama para nabi dan rasul yang diutus ke muka bumi. Di sisi lain, sejarah telah mencatat bahwa kaum-kaum yang dibinasakan oleh Allah Swt., di dalam Al-Quran, umumnya memiliki problemtika yang sama, yaitu mereka menyembah kepada sesuatu selain Allah Swt. Perbuatan syirik ini seolah menjadi penyakit turun-temurun, sehingga tidak ada satu kaum yang diutus kepada mereka seorang nabi yang mengajak untuk beriman kepada Allah Swt., justru akan melakukan hal yang sebaliknya. Oleh karena itu, pemurnian akidah atau tauhid menjadi misi utama yang diemban oleh para nabi dan rasul. Allah Swt., berfirman di dalam Al-Quran:

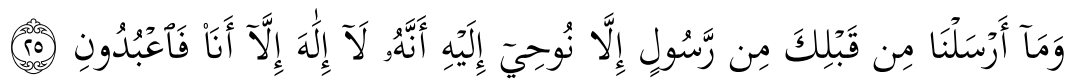

Artinya: dan Kami tidak mengutus seorang Rasulpun sebelum kamu melainkan Kami wahyukan kepadanya: "Bahwasanya tidak ada Tuhan (yang hak) melainkan Aku, Maka sembahlah olehmu sekalian akan aku". (Q.S. al-Anbiyaa': 25)

Dari ayat di atas sudah jelas bahwa tujuan utama diutusnya para nabi dan rasul adalah untuk menyuarakan kemurnian akidah dan tuahid. Ibnu 
Katsir mengatakan bahwa:8 "Maka setiap kitab suci yang diturunkan kepada setiap nabi yang diutus semuanya menyuarakan bahwa tidak ada Ilah (yang benar) selain Allah, akan tetapi kalian -wahai orang-orang musyrik- tidak mau mengetahui kebenaran itu dan kalian justru berpaling darinya...".

Imam al-Baghawy juga mengatakan bahwa makna dari perintah Allah "sembahlah Aku" adalah "tauhidkanlah Aku". 9

Oleh karena itu sejarah telah mencatat bahwa seruan pertama kali yang dilontarkan Nabi Nuh kepada kaumnya adalah sembahlah Allah Swt., seperti yang tercantum di QS. Al-A'raf ayat 59. Hal ini menegaskan bahwa misi utama nabi Nuh diutus kepada kaumnya sama seperti misi para nabi sebelumnya yaitu mengajak kaumnya untuk mengesakan Allah dan melarang mereka untuk berbuat syirik. Nabi Nuh mengabarkan kepada kaumnya bahwa akan tiba suatu masa dimana mereka akan menghadap kepada Allah Swt., untuk mempertanggungjawabkan apa yang mereka perbuat.

Mengesakan Allah Swt., dan tidak menyekutukanNya dengan sesuatu apapun merupakan pendidikan dasar yang harus diberikan kepada peserta didik. Sudah menjadi kewajiban orang tua untuk selalu mengarahkan anaknya kepada jalan yang benar serta menanamkan kesadaran kepada anak tentang statusnya sebagai hamba yang harus melaksanakan kewajiban dan menjauhi apa yang dilarangnya. Juga, kesadaran setiap individu tentang kedudukan iman yang lurus sangat penting di dalam kehidupan. Dengan iman pekerjaan yang baik akan dihitung sebagai amal dan tampa iman pekerjaan apapun tidak akan dihitung sebagai amal kebajikan.

\section{2) Beriman kepada hari Pembalasan}

Sebagai seorang mikmin dituntut untuk mempercayai serta mengimani hal ghaib. Mempercayai perkara yang ghaib merupakan satu dari rukun iman yang enam, yaitu beriman kepada malaikat dan kepada hari kiamat. Allah Swt., berfirman:

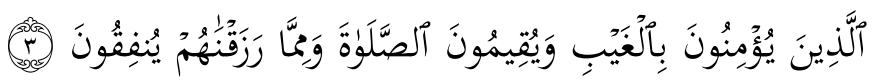

${ }^{8}$ Lihat Ibnu Katsir, Tafsir Al-Quran Al-'Azhim, (Dar Thaibah), Jilid. 5, hlm. 337

9 Al-baghawy, Abi Muhammad al Husein bin Mas'ud. Tafsiri al Baghawy Ma'alim atTanzil. (Dar Thebah), hlm. 834 
FITR AH Jurnal Kajian Ilmu-ilmu Keislaman

Vol. 03 No. 1 Juli 2017

Artinya: (yaitu) mereka yang beriman kepada yang ghaib, yang mendirikan shalat, dan menafkahkan sebahagian rezki yang Kami anugerahkan kepada mereka. (Q.S. al-Baqarah: 3)

Pada ayat di atas seorang mukmin diperintahkan untuk mengimani serta mempercayai perkara yang ghaib. Percaya kepada yang ghaib yaitu, meyakini adanya sesuatu yang tidak dapat ditangkap oleh pancaindera, berdasarkan ada dalil yang menunjukkan keberadaanya, seperti: adanya Allah, malaikat-malaikat, hari akhirat dan sebagainya. Syekh Thanthawy mengatakan bahwa ${ }^{10}$ percaya kepada perkara ghaib adalah asal dari iman. Apabila seseorang dapat menerima yang tak dapat dirasa serta meyakini keberadaanya, menerima yang terindra akan jauh lebih mudah baginya.

Allah Swt., berfirman ketika menceritakan dialog Nabi Nuh dengan kaumnya sebagai ajakan kepada mereka untuk mengimani yang ghaib dan mempercayainya.

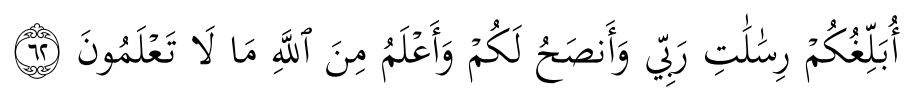

Artinya: "Aku sampaikan kepadamu amanat-amanat Tuhanku dan aku memberi nasehat kepadamu dan aku mengetahui dari Allah apa yang tidak kamu ketahui". (Q.S. al-A'raf: 62)

Imam al-Qosimi menjelaskan pengertian dari potongan ayat "dan aku mengetahui dari Allah apa yang tiak kamu ketahui." Yaitu aku mengetahui perkara-perkara yang ghaib yang tidak diketahui kecuali dengan perantara wahyu, aku mengetahui banyak hal yang tidak kalian ketahui, dan aku mengetahui kekuasaan Allah dengan dahsyatnya siksanya terhadap musuhmusuh-nya dan azabnya tidak dapat ditolak oleh orang-orang jahat lagi kafir apa yang tiadak kalian ketahui. ${ }^{11}$

Buah dari keimanan yang sudah ternaman di dalam hati akan mengantarkan seseorang tersebut untuk meyakini bahwa segala pekerjaanya akan dipertanggungjawabkan. Pertanggung jawaban yang dimaksud adalah dimana seseorang akan mendapatkan balasan dari segala sesuatu yang mereka kerjakan di muka bumi. Pada hari itu akan sangat jelas siapa saja

${ }^{10}$ Sayyid Thanthawy, at-Tafsir al-Washith (Cairo), Jilid. 1

11 Al-Qasimi, Muhammad bin Muhammad Said bin al-Qasim al-Damsyuqi. Mahasin alTa'wil fi Tafsir Quran al-Karim. Jilid. 7 hlm. 160 
orang yang mendapatkan kemenangan dan siapa saja yang bakalan merugi. Allah Swt., berfirman:

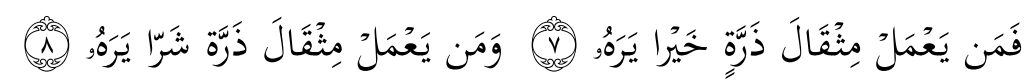

Artinya: Barangsiapa yang mengerjakan kebaikan seberat dzarrahpun, niscaya Dia akan melihat (balasan)nya. dan Barangsiapa yang mengerjakan kejahatan sebesar dzarrahpun, niscaya Dia akan melihat (balasan)nya pula. (Q.S. al-Zalzalah: 7-8)

Namun di sisi lain, kita juga harus mengimani bahwa balasan dari amal baik yang kita kerjakan atau amal buruk yang kita lakukan juga dapat bersifat pendek (di dunia) dan dapat bersifat panjang (di akhirat). Allah Swt., berfirman:

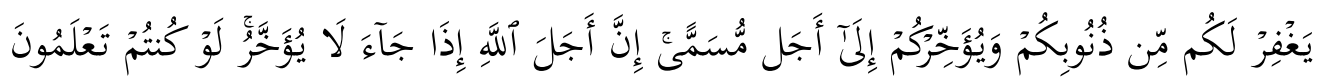

Artinya: niscaya Allah akan mengampuni sebagian dosa-dosamu dan menangguhkan kamu sampai kepada waktu yang ditentukan. Sesungguhnya ketetapan Allah apabila telah datang tidak dapat ditangguhkan, kalau kamu Mengetahui". (Q.S. Nuh: 4)

Ibnu Kasir ketika menafsiri ayat mengatakan: “dan menangguhkanmu sampai pada waktu yang ditentukan. "Yakni, memperpanjang umur kalian dan menunda ditimpakannya azab kepada kalian yang jika kalian tidak menghindari berbagai hal yang dilarangnya, pasti dia akan menimpakannya kepada kalian. Dan firman Allah Taala: “sesungguhnya apabila telah datang ketetapan Allah tidak dapat ditangguhkan, seandainya kamu mengetahui. " Maksudnya, bersegeralah kalian untuk berbuat taat sebelum penderitaan itu ditimpakan. Sebab, jika Allah Taala telah memerintahkan penimpaannya, niscaya tidak akan ada yang mampu menolak dan menahannya, karena dia maha Agung, Rabb yang menguasai segala sesuatu. Yang Maha Perkasa, karena Keperkasaannya semua mahluk tunduk kepadanya. ${ }^{12}$

\section{Nilai-nilai Pendidikan Ahlak}

\section{1) Lemah Lembut dalam Berdakwah}

Sepanjangan perjalanan dakwah yang dilakoni oleh Nabi Nuh senantiasa menggunakan kata-kata yang lembut, meskipun cacian demi cacian yang diterima dari kaumnya, namun Nabi Nuh tetap teguh dengan

\footnotetext{
${ }^{12}$ Imam Ibnu Kasir, Tafsir Ibnu Kasir, terj., M. Abdul Ghoffar E.M dkk, Op. Cit., hlm. 296,
} jilid 8 
FITR AH Jurnal Kajian Ilmu-ilmu Keislaman

Vol. 03 No. 1 Juli 2017

pendiriannya yang semula untuk tidak bosan dan putus asa mengajak mereka dengan penuh kelembutan.

Salah satu ungkapan yang menarik sebagai bukti kelemah lembutan seruan yang digencarkan oleh Nabi Nuh adalah seperti firman Allah Swt.:

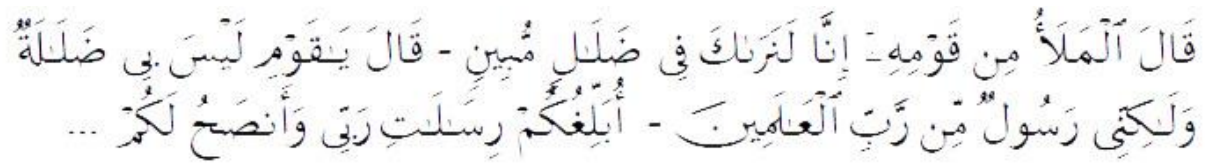

Ayat di atas menggambarkan betapa Nabi Nuh di dalam berdakwah penuh dengan kelemah lembutan, kesabaran dan jauh dari keputus asaan. Ketika Nabi Nuh dituduh oleh kaumnya dengan tuduhan keji "sesungguhnya kami memandang kamu berada dalam kesesatan yang nyata", namun tuduhan keji itu jangankah untuk membalas tuduhan mereka kemarahan pun tidak kita temukan pada dirinya, Nabi Nuh seraya menjawab: "Hai kaumku, tak ada padaku kesesatan sedikitpun tetapi aku adalah utusan dari Tuhan semesta alam". "Aku sampaikan kepadamu amanat-amanat Tuhanku dan aku memberi nasehat kepadamu.

Bersikap lemah lembut kepada sesama manusia merupakan ahlak terpuji yang diajakan oleh Rasulullah Swa. Allah Swt., menegaskan kepada Nabi Muhammad kalau seandainya Rasulullah tidak berlaku lemah lembut dalam berdakwah niscaya orang-orang kafir akan meninggalkannya. Hal ini seperti yang terdapat pada surah Ali Imron:

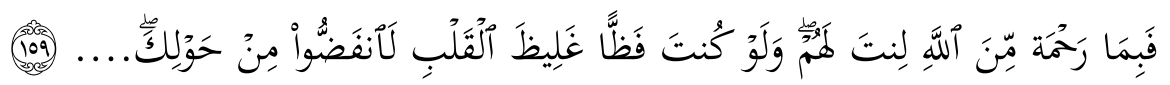

Artinya: Maka disebabkan rahmat dari Allah-lah kamu Berlaku lemah lembut terhadap mereka. Sekiranya kamu bersikap keras lagi berhati kasar, tentulah mereka menjauhkan diri dari sekelilingmu... (Q.S. Ali Imran: 159)

Betapa pentingnya sikap lemah lembuh di dalam berinteraksi dengan sesama manusia; baik antara seorang guru dengan siswanya, dosen dengan mahasiswanya, pekerja dengan pekerja lainnya, atasan dengan bawahannya, pejabat pemerinta dengan warganya. Oleh karena itu, kelemah lembutan di dalam mengajar, berdakwah dan menyampaikan nilai-nilai kebaikan adalah sebuah keniscayaan. Betapa banyak perkara positif namun berubah menjadi negatif karena kesalahan di dalam menyampaikannya. Oleh karena itu dapat dipastikan bahwa sikap lemah lembut menjadi satu sikap yang menghiasi manusia di dalam segala aspek kehidupannya. 


\section{2) Sabar}

Sifat sabar merupakan sifat yang tidak boleh lepas dari seorang penyeru kepada jalan kebaikan. Baik ia guru, dosen, dai dan segala profesi yang bersentuhan dengan tantangan dan rintangan. Kesabaran ini juga akan menjadi penetu derajat kita di sisi Allah Swt. Allah Swt., berfirman di dalam Al Quran:

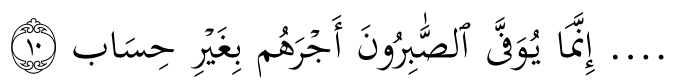

Artinya: ... Sesungguhnya hanya orang-orang yang bersabarlah yang dicukupkan pahala mereka tanpa batas. (Q.S. az-Zumar: 10)

Di sisi lain juga kita menemukan ada sebutan Rasul Ulul 'Azmi, yang mana penamaan ini berdasarkan keteguhan serta kesabaran mereka di dalam menyebarkan risalah ilahi. Syekh Thanthawy mengatakan: ${ }^{13}$ ulul 'azmi adalah mereka yang memiliki keteguhan, ketabahan serta kesabaran yang tinggi atas segala rintangan dan cobaan, yaitu Nabi Nuh, Ibrahim, Musa, Isa dan Muhammad Saw. Allah Swt., berfirman:

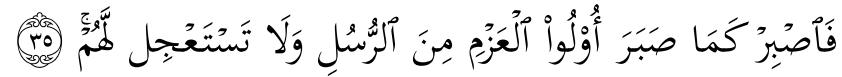

Artinya: Maka bersabarlah kamu seperti "rasul ulul 'azmi" yang telah bersabar dan janganlah kamu meminta disegerakan (azab) bagi mereka... (Q.S. al-Ahqaab: 35)

Tidak diragukan lagi betapa sabarnya Nabi Nuh di dalam mengajak kaumnya untuk beriman kepada Allah Swt. Hal ini dapat dilihat dari dua sisi yang: 1. Lamanya waktu berdakwah Nabi Nuh, 2. Sedikitnya yang beriman dari kaum Nabi Nuh. Allah Swt., berfiman:

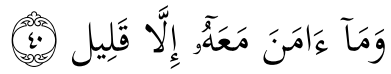

Artinya: ... dan tidak beriman bersama dengan Nuh itu kecuali sedikit (Q.S.

Huud: 40)

Sedangkan ayat yang menjelaskan berapa lama waktu yang digunakan Nabi Nuh di dalam berdakwah terdapat pada firman Allah Swt.:

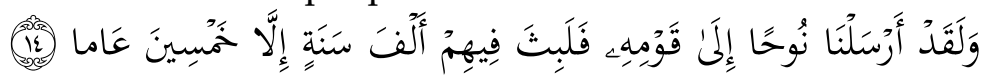

Artinya: dan Sesungguhnya Kami telah mengutus Nuh kepada kaumnya,

Maka ia tinggal di antara mereka seribu tahun kurang lima puluh tahun... (Q.S. al-'Ankabut: 14)

\footnotetext{
${ }^{13}$ Sayyid Thanthawy, at-Tafsir al-Washith (Cairo), Jilid. 1
} 
FITR AH Jurnal Kajian Ilmu-ilmu Keislaman

Vol. 03 No. 1 Juli 2017

Allah Swt., telah menganugrahkan kesabaran kepada para rasul untuk menghadapi berbagai kesulitan dan penderitaan. Dia memberi kekuatan untuk menghadapi musuh sehingga dapat menyampaikan risalah dengan sempurna. Dia juga menyempernukan mereka dengan kasih sayang yang tidak terbatas dan hati yang selalu berharap rahmatNya. Dengan begitu, tidak ada alasan lagi bagi manusia untuk mengelak dihadapan Allah setelah Dia mengutus para rasul. Tidak ada lagi dalih bagi orang-orang kafir setelah mereka mendatangi mereka. ${ }^{14}$

Sabar dalam menghadapi segala ujian, merupakan nilai-nilai ahklak Islami yang bisa mengantarkan manusia kepada keberuntungan. Sabar bisa berati menahan, artinya menahan diri dari sifat marah ketika dizhlimi oleh orang lain. Allah memberikan kabar gembira bagi orang-orang yang lebih mendahulukan kesabaran daripada emosi. Jika peserta didik dididik untuk selalu bersikap sabar dalam segi apapun maka akan melatihnya untuk menjadi insan yang berahlakul karimah sesuai dengan apa yang dicontohkan oleh Rasul.

\section{Nilai-nilai Pendidikan Ibadah}

\section{1) Perintah Amar Ma'ruf Nahi Mungkar}

Kisah perjuangan Nabi Nuh berdakwah kepada kaumnya untuk mengesakan Allah merupakan pelajaran penting kepada setiap orang yang mengajak kepada jalan kebaikan. Kisah ini Allah abadikan di dalam surah nuh, Allah Swt., berfiman:

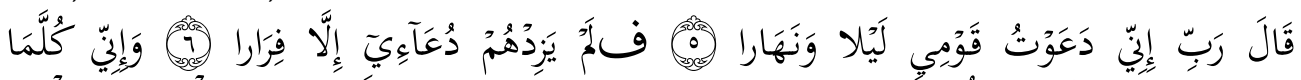

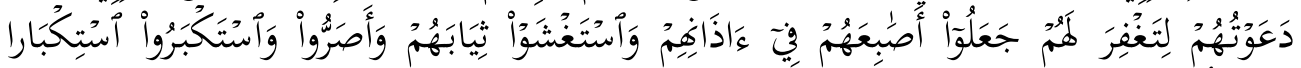

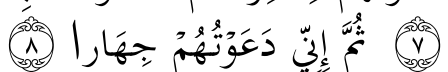

Artinya: Nuh berkata: "Ya Tuhanku Sesungguhnya aku telah menyeru kaumku malam dan siang. Maka seruanku itu hanyalah menambah mereka lari (dari kebenaran). dan Sesungguhnya Setiap kali aku menyeru mereka (kepada iman) agar Engkau mengampuni mereka, mereka memasukkan anak jari mereka ke dalam telinganya dan menutupkan bajunya (kemukanya) dan mereka tetap (mengingkari) dan menyombongkan diri dengan sangat. kemudian Sesungguhnya aku telah menyeru mereka (kepada iman) dengan cara terangterangan. (Q.S. Nuh: 5-8)

14 Lihat Muhammad Ahmad Jadul Maula, dkk. Kisah-kisah Al-Quran, terj., AbdurrahmanAssegaf, (Jakarta: Zaman, 2009), hlm. 40 
Nilai pendidikan ibadah yang terkandung di dalam ayat ini sangatlah jelas, yaitu perintah untuk amar ma'ruf nahi mungkar. Dia (Nuh) terus mengajak mereka kembali kepada Allah siang dan malam, secara sembunyisembunyi maupun terang-terangan. Dia mengarahkan pandangan kaumnya kepada rahasia eksistensi dan penciptaan alam semesta: Malam yang gelap gulita, langit yang bertabur bintang, rembulan yang beredar pada porosnya, matahari yang bersinar, hamparan bumi yang memancarkan air sungai dan diatasnya tumbuh berbagai macam tanaman dan buah-buahan. Semua ini disampaikannya dengan bahasa fasih dan lancar. Dia berbicara dengan bukti-bukti yang benar tentang Tuhan yang maha Esa dan tentang kekuatan satu-satunya yang mengagumkan. ${ }^{15}$

Perintah untuk amar ma'ruf dan nahi mungkar ini jelas bernilai ibadah, namun perintah ini tidak hanya bertujuan untuk mendapatkan pahala di sisi Allah Swt., akan tetapi upaya manusia agar kelak di hapadan Allah Swt., tidak disiksi akibat melalaikan perintah mengajak kepada kebaikan dan mencegah dari yang mungkar. Allah Swt., berfirman:

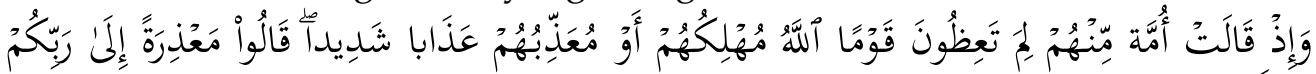

وَلَعَلَّهُمْ يَتَّقُونَ

Artinya: dan (ingatlah) ketika suatu umat di antara mereka berkata: "Mengapa kamu menasehati kaum yang Allah akan membinasakan mereka atau mengazab mereka dengan azab yang Amat keras?" mereka menjawab: "Agar Kami mempunyai alasan (pelepas tanggung jawab) kepada Tuhanmu, dan supaya mereka bertakwa. (Q.S. al-A'raaf: 164)

Sudah sepatutnya bagi seorang penyeru kepada jalan kebaikan untuk tidak berputus asa. Hal ini seperti yang dicontohkan oleh Nabi Nuh yang tidak mengenal waktu dalam mengajak kaumnya menuju jalan yang diridhai oleh Allah Swt. Kegigihan serta ketekukan Nabi Nuh layak dijadikan sebagai bahan renungan dan 'ibrah kepada juru dakwah, guru, dosen atau profesi lainnya di dalam mengemban serta menjalankan penyebar luasan risalah kebenaran.

Ibnu Kasir mengatakan: Allah Taala mengabarkan seorang hamba sekaligus Rasulnya, dimana Nuh pernah mengadu kepada rabbnya yang

15 Ali Muhammad al-Bajawi ,dkk. Untaian Kisah dalam Al-Quran, terj., Abdul Hamid, (Jakarta: Darul Haq, 2007), hlm. 21 
FITR AH Jurnal Kajian Ilmu-ilmu Keislaman

Vol. 03 No. 1 Juli 2017

maha Perkasa lagi mahamulia tentang perlakuan tidak menyenangkan yang dia terima dari kaumnya. Dan juga kesabarannya menghadap mereka selama masa yang cukup panjang, yaitu selama 950 tahun. Juga apa yangtelah dia jelaskan dan terangkan kepada kaumnya serta seruannya kepada kebenaran dan jalan yang lurus. ${ }^{16}$

Imam Al-Qosimi juga mengatakan dalam menggambarkan bagaimana usaha maksimal nabi Nuh dalam berdakwah. Sebagaimana yang tertulis didalam tafsir Al-Qosimi: "Artinya beliau mendakwahi mereka setahap demi setahap, siang malam dengan variasi antara terus terang tanpa menutup-nutupi, mengumumkan dan berteriak ditengah mereka atau merahasiakan antar mereka dengan sembunyi-sembunyi. Semua tahapan dan variasi dalam metode dakwah ini adalah usaha maksimal. dari orang yang mengajak amar makruf nahi mungkar untuk mempraktekkannya agar lebih sukses dalam dakwahnya." 17

\section{2) Mendidik anak dengan baik}

Di dalam Al-Quran sudah dijelaskan betapa anak adalah sebuh anugerah terindah Allah Swt., kepada manusia. Sehingga banyak di antara doa-doa para nabi yang diabadikan di dalam Al-Quran sebagai bukti kengingina mereka untuk memperolah anak keturunan, di antaranya doa Nabi Ibrahim, Nabi Zakariya.

Namun di waktu yang sama, anak sebagai anugerah juga dapat menjadi malapetaka bagi kedua orang tua. Karena sejatinya anak keturuan juga dapat menjadi jalan masuknya ujian serta bala kepada orang tua. Allah Swt., berfirman:

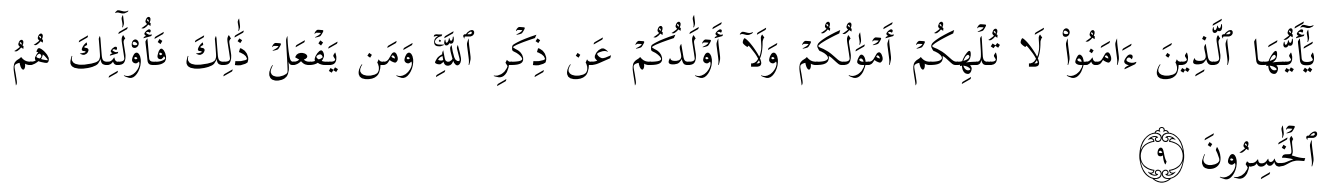

Artinya: Hai orang-orang beriman, janganlah hartamu dan anak-anakmu melalaikan kamu dari mengingat Allah. Barangsiapa yang berbuat demikian Maka mereka Itulah orang-orang yang merugi. (Q.S. al-Munafiquun: 9)

16 Imam Ibnu Kasir, Tafsir Ibnu Kasir, terj., M. Abdul Ghoffar E.M dkk, Op. Cit., hlm. 299 , jilid 8

17 Al-Qasimi, Muhammad bin Muhammad Said bin al-Qasim al-Damsyuqi. Mahasin alTa'wil fi Tafsir Quran al-Karim. jilid 16 hlm. 295 
Dari ayat di atas dapat dipahami bahwa mendidik anak dengan baik merupakan kewajiban orang tua, juga dapat bernilai ibadah. Dari perjuangan Nabi Nuh mengajak serta menasehati anaknya agar beriman kepada Allah Swt., dapat dipetik sebuah pelajaran penting khsusunya terhadap orang tua. Jika seseorang yang setiap harinya berada dibawah pengawasan seorang nabi pun tidak menjadi jaminan terhindar dari Azab Allah Swt., maka bagaimana bisa seorang yang bukan nabi melalaikan kewajibannya mendidik anaknya. Allah Swt., berfirman:

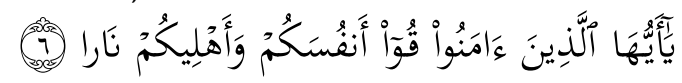

Artinya: Hai orang-orang yang beriman, peliharalah dirimu dan keluargamu dari api neraka... (Q.S. at-Tahriim: 6)

Di dalam ayat yang lain Allah Swt., berfiman:

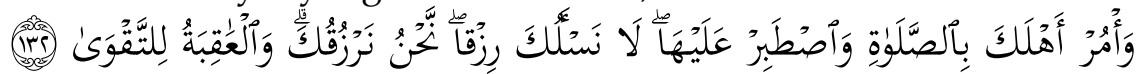

Artinya: dan perintahkanlah kepada keluargamu mendirikan shalat dan bersabarlah kamu dalam mengerjakannya. Kami tidak meminta rezki kepadamu, kamilah yang memberi rezki kepadamu... (Q.S. Thaha: 132)

Kedua ayat di atas sudah cukup menjadi dalil bahwa mendidik anak serta membentengi mereka dengan keimanan menjadi kewajiban orang tuanya, sehingga mereka kelak terpelihara dari siksa akhirat.

\section{PENUTUP}

Ungkapan bahwa Al Quran sebagai pedoman hidup dan referensi utama di dalam berbagai aspek kehidupan bukanlah ungkapan kosong dan inrealistis. Dakwah Nabi Nuh adalah salah satu bukti konkrit ungkapan tersebut. Metode dakwah yang diterapkan Nabi Nuh tidak lepas dari gambaran pendidikan yang mesti dipelajari serta dikaji para pendidik. Secara tidak langsung bahwa Allah Swt., mengajari para pendidik untuk memperhatikan banyak hal sebelum menyampaikan apa yang hendak disampaikan.

Benar bahwa dunia pendidikan membutuhkan pendidik yang handal dan kompeten di bidangnya, mahir serta memiliki kecakapan di dalam mentransfer of know ladge kepada peserta didik. Juga tidak diragukan bahwa para pendidik memegang perang penting dalam menghantarkan peserta didik menjadi orang yang mempunyai wawasan yang luas dan keilmuan yang dalam. Namun, para pendidik juga harus memiliki tujuan di dalam 
FITR AH Jurnal Kajian Ilmu-ilmu Keislaman

Vol. 03 No. 1 Juli 2017

melaksanakan proses pendidikan seperti metode yang sudah digunakan Nabi Nuh, mulai dari penanaman akidah, penumbuhan nilai-nilai akhlak serta ibadah. Karena sejatinya ilmu dipelajari bertujuan agar peserta didik memiliki pegangan akidah yang kokoh serta memiliki akhlak yang mulia serta ibadah yang terjaga dan meningkat. 


\section{DAFTAR PUSTAKA}

Abdul Mujib, dan Muhaimin. Pemikiran Pendidikan Islam, Bandung: Trigenda Karya, 1993.

Al-baghawy, Abi Muhammad al Husein bin Mas'ud. Tafsiri al Baghawy Ma'alim at-Tanzil. (Dar Thebah)

Al-Bajawi, Ali Muhammad, dkk. Untaian Kisah dalam Al-Quran, terj., Abdul Hamid, Jakarta: Darul Haq, 2007.

Al-Qasimi, Muhammad bin Muhammad Said bin al-Qasim al-Damsyuqi. Mahasin al-Ta'wil fi Tafsir Quran al-Karim jilid 7

An-Nahlawi, Abdurrahman. Usulu al-Tarbiyah al-Islamiyah wa Asaalibuha Fii alBait wa al-Madrasah wa al-Mujtama', (Dimasyq: Dar al-Fikr, 1979), Cet. Ke-1

Arifin, M. Ilmu Pendidikan Islam: Suatu Tinjauan Teoritis dan Praktis Berdasarkan Pendekatan Interdisipliner, Jakata: bumi Aksara, 2000.

Aziz Abd. Filsafat Pendidikan Islam; Sebuah Gagasan Membangun Pendidikan Islam, (Yogyakarta: TERAS, 2009)

Hailami Moh. \& Syamsul Kurniawan, Studi Ilmu Pendidikan Islam, Jogjakarta: ArRuzz Media, 2012.

Ibnu Katsir, Tafsir Al-Quran Al-`Azhim, (Dar Thaibah), Jilid. 5

Ihsan, Hamdani dan A. Fuad Ihsan. Filsafat Pendidikan Islam, Bandung: CV. Pustaka Setia, 1998.

Imam Ibnu Kasir, Tafsir Ibnu Kasir, terj., M. Abdul Ghoffar E.M dkk, jilid 8

Jadul Maula, Muhammad Ahmad dkk. Kisah-kisah Al-Quran, terj., AbdurrahmanAssegaf, Jakarta: Zaman. 2009.

Muhaimin, Pendidikan Islam: Mengurangi Benang Kusut Dunia Pendidikan, Jakarta: PT Raja Grafindo Persada. 2006.

Sayyid Thanthawy, at-Tafsir al-Washith (Cairo), Jilid. 1 
FITR AH Jurnal Kajian Ilmu-ilmu Keislaman

Vol. 03 No. 1 Juli 2017

Strategi Bersaing dalam Meningkatkan Jumlah Nasabah PT. Bank Sumut Cabang Syariah Padangsidimpuan

BUDI GAUTAMA SIREGAR 